\title{
Pneumologia
}

\section{Romanian Society of Pneumology respect its traditional activities}

Florin Mihălțan*, Ruxandra Ulmeanu

National Institute of Pneumology "Marius Nasta", Bucharest, Romania

\section{WEBINAR}

\section{a IX-a Conferință Managementul Bolilor Pulmonare}

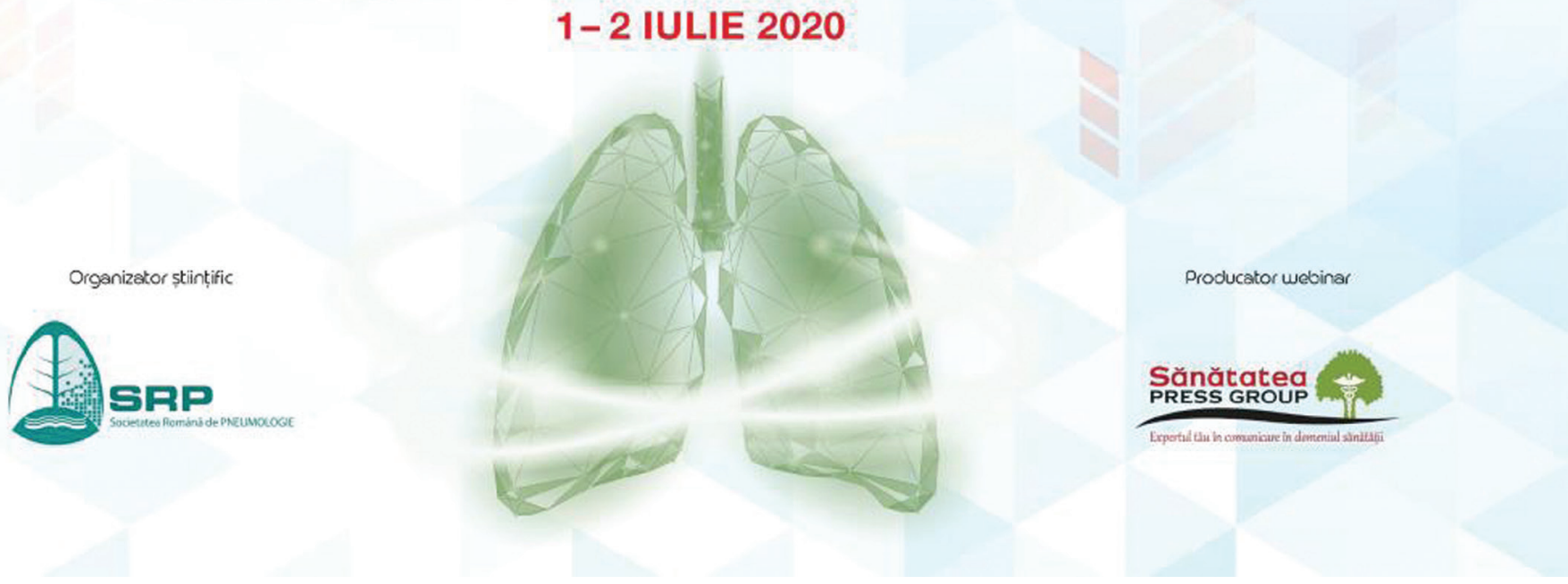

Even though coronavirus disease-2019 (COVID-19) is coming with its second wave, the Romanian Society of Pneumology continues to respect the calendar of traditional events. The ninth edition of the Conference on Management of Chronic Diseases has been successfully conducted. COVID-19 has changed our private and scientific life. Therefore, this edition was conducted online. The programme was very attractive, with the presence of $>350$ participants in this live session. The advantage of this type of webinar was the presence also of other specialties such as internal medicine, labour medicine, allergology and general practitioner (GP).
We had a variety of topics and sessions. On the first day, we started with an asthma session, with many interesting topics offered, such as difficult to treat asthma or severe asthma (by Ruxandra Ulmeanu), profile of severe asthma (by Roxana Nemes) and characteristics of asthma treatment in the COVID-19 pandemic (by Claudia Toma). Another session covered topics on bronchoscopic techniques and the diagnosis of different respiratory diseases such as tracheal tumours (by Petronela Fildan), interstitial lung diseases (by Mihai Alexe), criobiopsy (by Marioara Simon) and autofluoroscopy (by

${ }^{*}$ Corresponding author: Florin Mihaltan

E-mail:mihaltan@starnets.ro 
Camelia Badescu). On the next day, we had a session on tuberculosis (TB) (connected to the following: smoking: loana Munteanu; COVID-19: Adriana Socaci; and therapies in multi-drug-resistant TB: Cristina Popa), chronic obstructive pulmonary disease (COPD) (reahibilitation: Mimi Nitu; COVID effects: Florin Mihaltan; auto management: Doina Todea) and sleep disorders (by Gabriela Jimboreanu). Other important sessions were on lung cancer (solitary nodule - Dorin Vancea; screening - Beatrice Mahler; COVID-19 pandemic consequences - Radu Crisan Dabija; and management in chest services - Cristian Oancea) and a 'varia' session with exposure to novelties in interstitial lung diseases (by Irina Strambu), pollution and smoking in COPD (by Antigona Trofor), functional investigation in the COVID-19 period (by Ovidiu Fira Mladinescu) and rehabilitation in this moment of coronavirus extension (by Alina Haulica). It was a wellorganised online event, confirming that our lung physicians are prepared also for telemedicine practice.

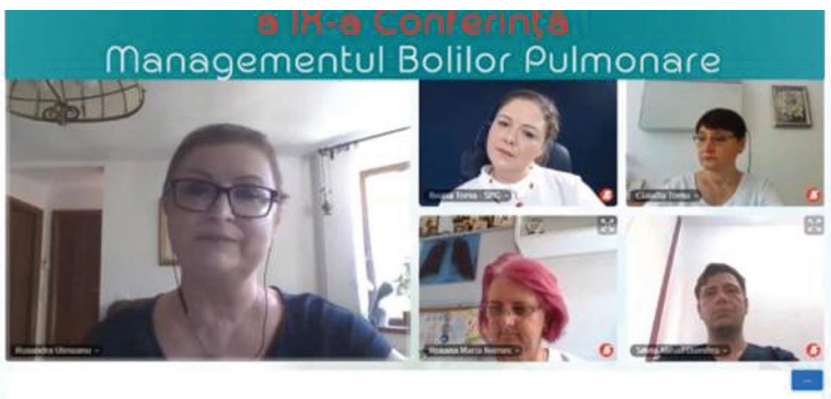

\section{Astm dificil de tratat \\ Astm necontrolat \\ sau}

Astm sever?

Ruxandra Ulmeanu

Silviu Mihail Dumitru

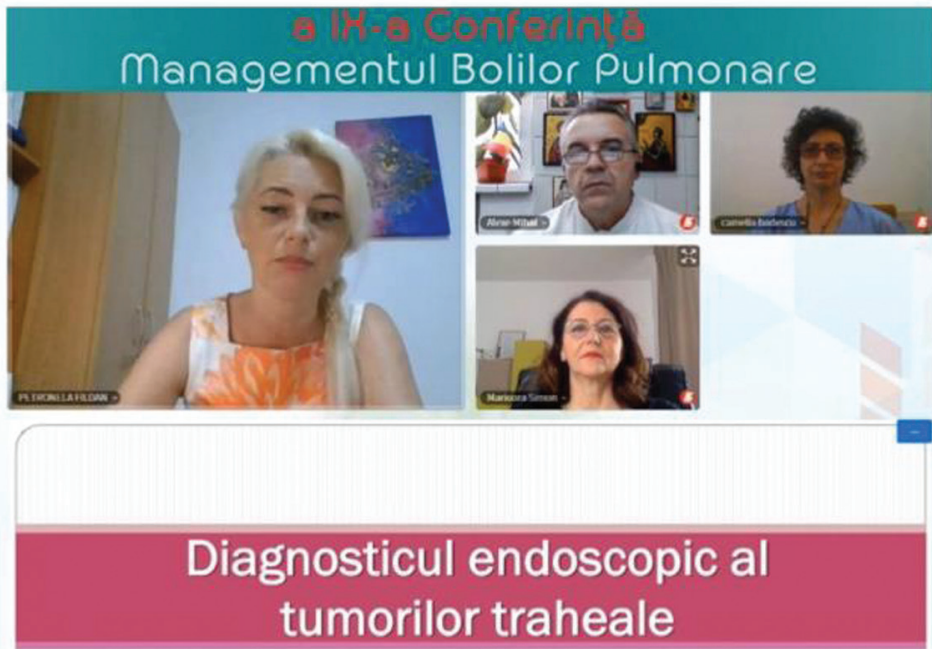

Ariadna Petronela Fildan Doina Tofolean 


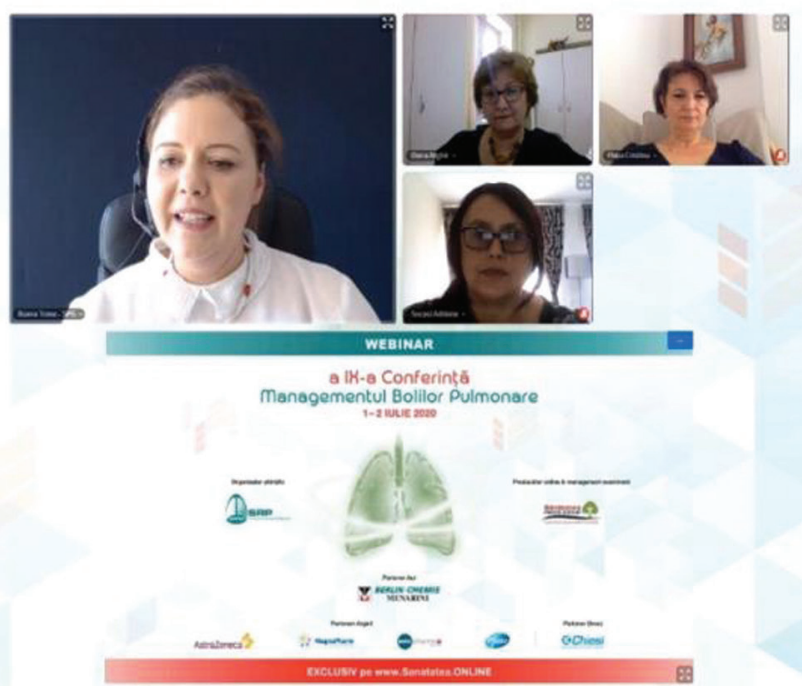

Organizator științific
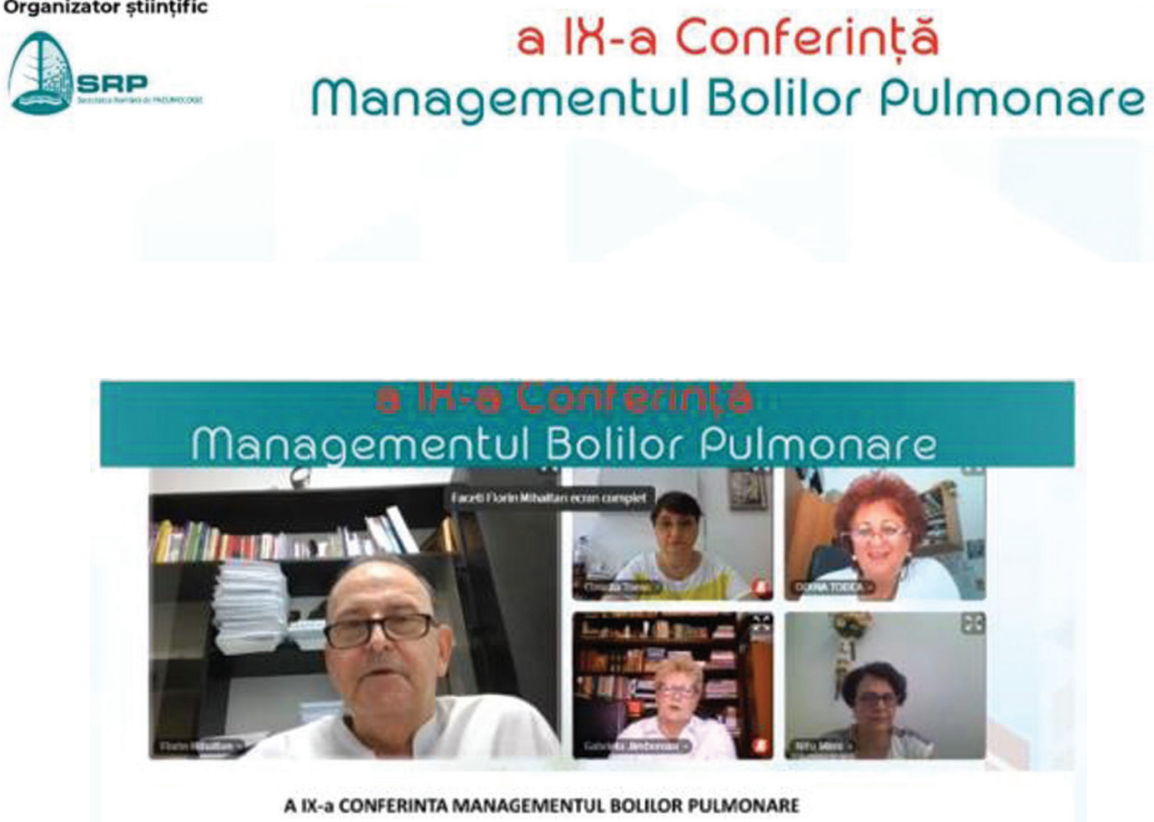

Locul terapiei duale in ghiduri si tratamentul adaptat fiecarui pacient cu BPOC

Prof Dr Florin Mihaltan mosc pies menumelec eesc vet wecte 


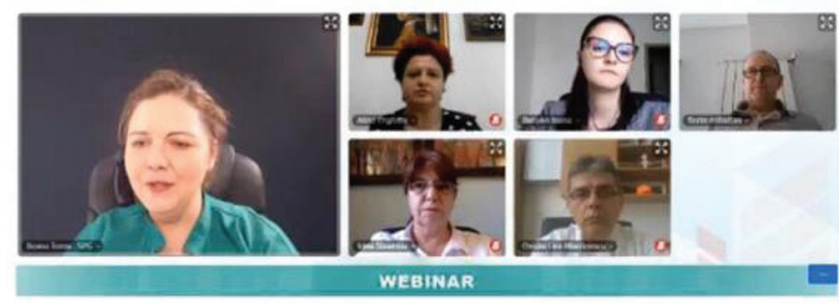

a IK-a Conferință

managementul Bolilor Pulmonare
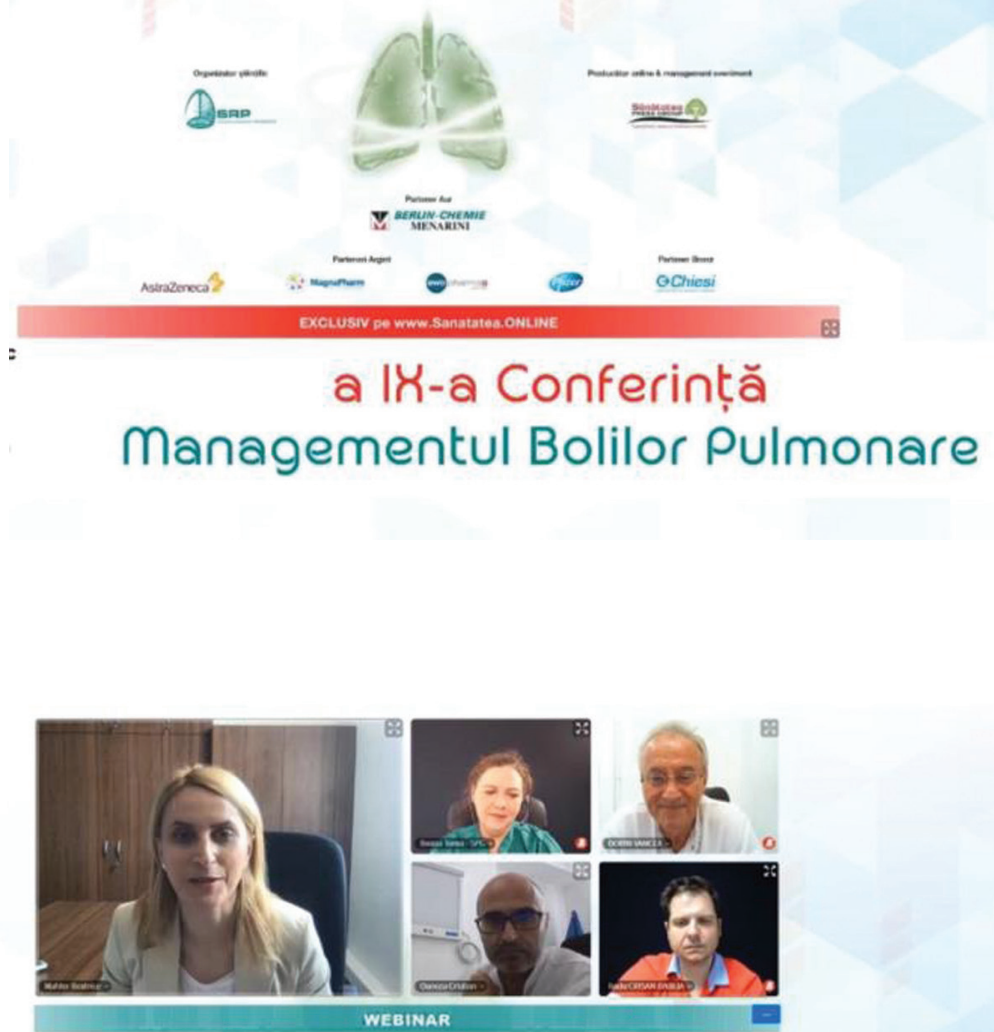

a Ix-a Conferințả

managementul Bolilor Pulmonare

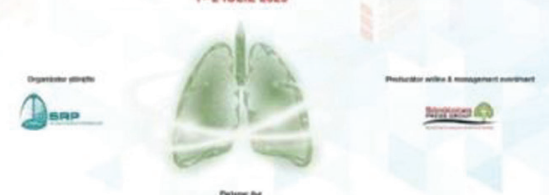

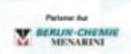

natronest

$2+\infty$

9

ochisesi

a IX-a Conferință

managementul Bolilor Pulmonare 